Review Article

\title{
Prevalence and Risk Factors of Lower Limb Amputation in Patients with End-Stage Renal Failure on Dialysis: A Systematic Review
}

\author{
Rajit A. Gilhotra, Beverly T. Rodrigues, Venkat N. Vangaveti, and Usman H. Malabu \\ School of Medicine and Dentistry, James Cook University, Townsville, QLD 4811, Australia \\ Correspondence should be addressed to Usman H. Malabu; umalabu@gmail.com
}

Received 8 April 2016; Accepted 30 June 2016

Academic Editor: Laszlo Rosivall

Copyright (C) 2016 Rajit A. Gilhotra et al. This is an open access article distributed under the Creative Commons Attribution License, which permits unrestricted use, distribution, and reproduction in any medium, provided the original work is properly cited.

Background. Renal dialysis has recently been recognised as a risk factor for lower limb amputation (LLA). However, exact rates and associated risk factors for the LLA are incompletely understood. Aim. Prevalence and risk factors of LLA in end-stage renal failure (ESRF) subjects on renal dialysis were investigated from the existing literature. Methods. Published data on the subject were derived from MEDLINE, PubMed, and Google Scholar search of English language literature from January 1, 1980, to July 31, 2015, using designated key words. Results. Seventy studies were identified out of which 6 full-text published studies were included in this systematic review of which 5 included patients on haemodialysis alone and one included patients on both haemodialysis and peritoneal dialysis. The reported findings on prevalence of amputation in the renal failure on dialysis cohort ranged from $1.7 \%$ to 13.4\%. Five out of the six studies identified diabetes as the leading risk factor for amputation in subjects with ESRF on renal dialysis. Other risk factors identified were high haemoglobin Alc, elevated c-reactive protein, and low serum albumin. Conclusions. This review demonstrates high rate of LLA in ESRF patients receiving dialysis therapy. It has also identified diabetes and markers of inflammation as risk factors of amputation in ESRF subjects on dialysis.

\section{Introduction}

End-stage renal failure, defined as nonreversible kidney damage requiring replacement therapy [1], is a recognised risk factor for peripheral artery disease leading to nonhealing ulcers and lower limb amputation (LLA) [2-6]. The aetiology of ESRF such as diabetes may be associated with complex vascular dysfunction and widespread organ involvement including cardiovascular and musculoskeletal systems, the two being the most important cause of morbidity and mortality in patients with ESRF on haemodialysis $[1,2,7]$.

The prevalence of diabetes globally, as reported by the International Diabetes Federation in 2015, was 415 million ( $8.3 \%$ of the world's adult population) and is projected to alarmingly rise to 642 million by 2040, a significant rise over a small period of time $[8,9]$. Diabetes is a leading cause of foot ulcer and renal failure amongst others [10]. In the case of foot ulcer, the combination of vascular insufficiency and local infection worsens the prognosis resulting in life threatening sepsis, LLA, and death [11-14]. Furthermore, the prevalence of foot complications in general is considerably higher in patients with diabetes and ESRF as compared to patients with diabetes without $\operatorname{ESRF}[5,6,13,14]$. It is known that LLA increases patient disability, decreases quality of life, and contributes to high morbidity, mortality, and health care costs [15-17] yet not much information on the extent of the problems is known worldwide.

Although various studies investigating the outcome of foot complications in patients with diabetes have been reported, prevalence of lower limb amputation in subjects on renal dialysis remains poorly recognised $[6,18]$. Furthermore, clinical and biochemical features accounting for the high rate of LLA in subjects on renal dialysis are inconclusive. This systematic review aimed to critically appraise published 
studies which have assessed LLA as an outcome in patients with ESRF on dialysis and to determine prevalence and risk factors associated with LLA in the study population.

\section{Methods}

2.1. Protocol and Focus. This systematic review was performed with the standardised written protocol that followed the Preferred Reporting Items for Systematic Reviews and Meta-Analyses (PRISMA) guidelines [25]. The review focuses on studies which assessed the prevalence and identified risk factors for lower limb amputation in patients who have received renal dialysis.

2.2. Search Criteria. A search strategy was formulated to identify studies in which LLA was assessed in patients with ESRF on dialysis. Databases from MEDLINE/PubMed (US National Library of Medicine, Bethesda, MD, USA) and Google Scholar (Google, Mountain View, CA, USA) were searched from January 1, 1980, to July 31, 2015. Keyword sets combined "diabetes" or "diabetic ulcer" or "diabetic foot" and "amputation" and "renal dialysis".

2.3. Eligibility Criteria. To be eligible, studies were required to focus on amputation as an outcome in ESRF patients on renal dialysis. For inclusion, studies had to be published before July 31, 2015. Publications were restricted to human studies and those published in English. There was no restriction on study size. For the inclusion of publications, the studies needed to be full articles which investigated patients on haemodialysis and/or peritoneal dialysis as a cohort and required recording of the prevalence and/or the risk factors associated with amputation as an outcome in this cohort.

Publications were excluded from this systematic review if they were review articles, looked at traumatic/neoplastic, only upper extremity/penile amputation as outcomes, compared prognosis of different interventions, and included only a subgroup of dialysis patients in the study (such as patients with diabetes on renal dialysis and patients on renal dialysis who had peripheral artery bypass).

2.4. Data Extraction. Data from the identified studies was extracted by one author. Any uncertainty was resolved by discussion between authors. Data extraction from eligible literature included information regarding geographical location, sample size, mean age, percentage of male patients, mean time on dialysis, diabetes mellitus, smoking history, hypertension, coronary artery disease, amputation, and risk factors (RR, OR, HR, RH, $p$ values, and confidence intervals). Data was transcribed into an excel data collection sheet.

\section{Results}

3.1. Search Results. Seventy published studies were identified as per the abovementioned search criteria (Figure 1). Fifty studies were excluded due to various reasons such as lack of investigating lower limb amputation as an outcome, dialysis/renal replacement/renal replacement therapy/end-stage renal failure/renal failure/end-stage kidney disease/kidney failure not being mentioned in the title, and comparing prognosis and outcomes of various pharmacological and surgical interventions. Abstracts were critically screened for the 20 remaining studies out of which another 14 were excluded due to being review articles $(n=6)$; being case studies $(n=2)$; only including a subset of dialysis patients $(n=2)$; not including dialysis patients $(n=1)$; assessing vascular changes in amputated limbs as an outcome $(n=1)$; assessing prognosis of percutaneous transluminal angioplasty as an outcome $(n=1)$; inability to access full text $(n=1)$. In all, 6 full-text publications were reviewed as detailed in Figure 1.

3.2. Characteristics of Included Studies and Subjects. Five out of the six studies included patients on haemodialysis [19-23] and one study included both haemodialysis and peritoneal dialysis patients [24]. There was no study that only included peritoneal dialysis patients.

As for the outcomes, two of the studies investigated only amputation in particular $[19,22]$ and the remaining four explored other outcomes as well such as foot problems, peripheral vascular disease related procedures, myocardial infarction, and mortality $[20,21,23,24]$. The data related to these outcomes was presented separately in all these studies; therefore, it was possible to assess data specific to amputation by itself. There was marked variation in sample size between studies. All studies included at least 100 subjects (Table 1). Two studies included between 100 and 500 patients $(n=271$, $n=232)[20,21]$, three studies had between 1000 and 5000 subjects $(n=1513, n=1041$, and $n=3272)[19,23,24]$, and one study had 29838 subjects [22]. Most publications sourced participants from hospital or dialysis clinics, apart from one study that was conducted on patients from a nursing home setting [21]. Three of the studies recruited participants from single centres $[20,21,23]$ and three from multiple centres [19, 22, 24]. Populations examined also varied between studies. Three studies focused on American patients [19, 21, 24]. Single studies recruited patients from Japan [23] and Canada [20]. One study included patients from around the world including 12 countries [22]. Three studies extracted data from larger studies such as the Choices for Healthy Outcomes in Caring for End-Stage Renal Disease (CHOICE) [24], Dialysis Outcomes and Practice Patterns Study (DOPPS) [22], and the ESRF Core Indicator/Clinical Performance Measure (CPM) Project [19].

All the studies were consistent in defining their inclusion criteria of patients on dialysis therapy; they all identified that patients with ESRF were placed on renal dialysis as a form of renal replacement therapy, that being either haemodialysis or peritoneal dialysis. The studies defined the endpoint being development of amputation, which could have been performed when uncontrollable limb infection existed even after undergoing revascularization and/or medical treatment. One publication specifically defined nontraumatic lower limb amputation and excluded digital amputation as one of the primary outcomes that were investigated [24]. Only one study specifically defined major amputation as above-theknee amputation [23]. 


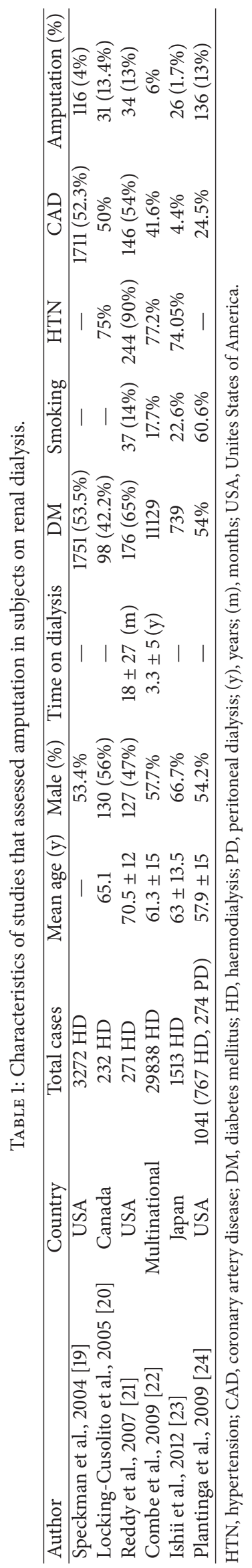




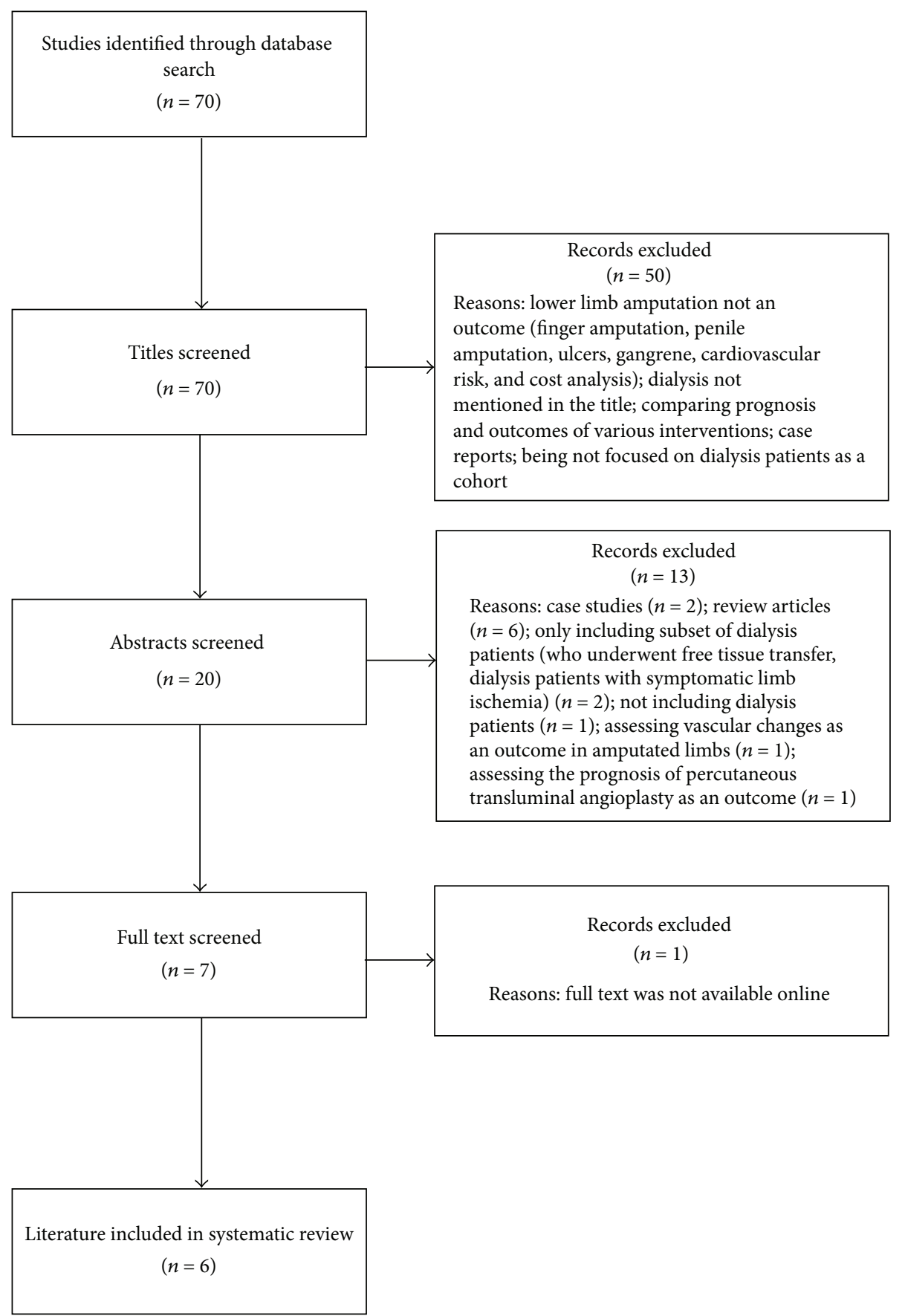

FIgURE 1: Flow diagram to illustrate the studies identified for this review.

Five of the studies were longitudinal cohort studies, out of which four were retrospectively designed $[19,21$, $22,24]$ and one of each of prospective longitudinal format [23] and observational case-control study [20], respectively. Although all the studies were investigated for comorbidities in the participant population, there were some variations in the different studies. The prevalence of comorbidities also varied from study to study; for example, only $4.4 \%$ [23] of participants in one study had coronary artery disease compared to $54 \%$ in another [21]. All the retrospective studies collected their data via databases or medical chart review. Locking-Cusolito and colleagues used a foot assessment instrument which was used in clinics to collect data from patients attending their clinic [20]. The prospective study had a follow-up time period of 96 months over which the data was collected via direct patient contact, medical charts, or telephonic interview.

3.3. Amputation in Subjects on Renal Dialysis. The reported finding on prevalence of amputation in patients with renal 
TABLE 2: Summary of studies assessing risk factors of amputation in subjects on renal dialysis.

\begin{tabular}{|c|c|}
\hline Author & $\begin{array}{l}\text { Risk factors for amputation in all dialysis } \\
\text { patients }\end{array}$ \\
\hline $\begin{array}{l}\text { Speckman et } \\
\text { al., } 2004 \text { [19] }\end{array}$ & $\begin{array}{l}\text { MUR }<58.5 \%: \text { HR } 2.4 \text { (CI 1.4-4.2), } p<0.01 \\
\text { CVD: HR 2.4 (CI 1.6-3.7), } p<0.001\end{array}$ \\
\hline $\begin{array}{l}\text { Combe et al., } \\
2009 \text { [22] }\end{array}$ & $\begin{array}{l}\text { DM: AOR } 5.55 \text { (CI } 4.63-6.64), p<0.001 \\
\text { Men: AOR } 1.82 \text { (CI 1.61-2.06), } p<0.001 \\
\text { Blacks: AOR } 1.45 \text { (CI 1.28-1.65), } p<0.001 \\
\text { Smoking: AOR } 1.22 \text { (CI 1.03-1.43), } p<0.001 \\
\text { Retinopathy: AOR } 1.78 \text { (CI 1.55-2.04), } \\
p<0.001 \\
\text { Peripheral neuropathy: AOR } 2.25 \text { (CI } \\
\text { 1.98-2.56), } p<0.001 \\
\text { Calciphylaxis: AOR } 2.37 \text { (CI 1.63-3.45), } \\
p<0.001\end{array}$ \\
\hline $\begin{array}{l}\text { Plantinga et } \\
\text { al., } 2009 \text { [24] }\end{array}$ & $\begin{array}{l}\text { DM: RH } 4.33 \text { (CI 2.98-6.30), } p<0.05 \\
\text { PVD: RH } 1.59 \text { (CI 1.17-2.15), } p<0.05 \\
\text { CRP: RH } 2.7 \text { (CI 1.72-4.23), } p<0.05 \\
\text { Albumin }<3.3 \text { g/dL: RH 0.63 (CI 0.42-0.94), } \\
p<0.05\end{array}$ \\
\hline $\begin{array}{l}\text { Locking- } \\
\text { Cusolito et } \\
\text { al., } 2005 \text { [20] }\end{array}$ & DM: AOR 10.17 (CI 3.7-27.7), $p<0.001$ \\
\hline $\begin{array}{l}\text { Ishii et al., } \\
2012[23]\end{array}$ & $\begin{array}{l}\text { DM: HR } 5.29 \text { (CI 2-13.9), } p=0.0008 \\
\text { CRP: HR 1.01 (CI 1-1.02), } p<0.05\end{array}$ \\
\hline $\begin{array}{l}\text { Reddy et al., } \\
2007[21]\end{array}$ & $\begin{array}{l}\text { Dialysis > } 12 \text { months: AOR } 2.74 \text { (CI 1.22-6.16), } \\
p<0.05\end{array}$ \\
\hline
\end{tabular}

DM, diabetes mellitus; HR, hazard ratio; $\mathrm{RH}$, relative hazard; AOR, adjusted odds ratio; PVD, peripheral vascular disease; CVD, cardiovascular disease; MUR, mean urea reduction; CI: 95\% confidence interval.

failure on renal dialysis was $1.7 \%$ to $13.4 \%$ (Table 1 ). Five out of the six studies that were included in the systematic review identified presence of diabetes mellitus as the leading risk factor for amputation $(p<0.05)[19,20,22-24]$. Although all the studies used different ratios to present their findings, there were two studies which used hazard ratios (HR). Ishii and colleagues and Speckman and colleagues reported that diabetic renal failure patients had a higher risk of getting amputation as compared to their counterparts without diabetes, HR 5.29, 95\% CI 2-13.9, $p=0.0008$, and HR 7.4, 95\% CI 4.1-13.5, $p<0.001$, respectively. On the other hand, Reddy and colleagues investigated the association of duration of renal replacement therapy and amputation as an outcome. They found that a higher percentage (19\%) of established haemodialysis patients (dialysis for $\geq 12$ months) had to have amputation as compared to new haemodialysis patients (8\%) (dialysis for $\leq 3$ months) $(p=0.01)$ [21].

\subsection{Risk Factors of Amputation in Subjects on Renal Dialysis.} Detailed risk factors are shown in Table 2. Diabetes was reported as a leading risk factor associated with amputation in renal dialysis patients in 5 out of the 6 studies. Two studies compared diabetic and nondiabetic subjects on dialysis showing higher rate of amputation amongst diabetics as shown in Table 3.
Other amputation risk factors reported in subjects on renal dialysis included longer duration of dialysis therapy, HbAlc levels, c-reactive protein (CRP), and low serum albumin. In patients with diabetes, a higher HbAlc level after commencement of dialysis was found to be statistically significant as a risk factor for amputation [20, 23]. Ishii and colleagues established that all patients requiring major amputation $(n=7)$ were found to fall in the highest HbAlc quartile (HbAlc > 6.8\%). Overall, 6.1\% of all amputees had an HbAlc $>6.8 \%$ as compared to only $0.9 \%$ of amputees with HbAlc $<5.4 \%$. The association of a higher HbAlc and amputation was also found to be statistically significant: HbAlc $>6.8 \%$, HR 2.99, 95\% CI 1.17-7.7, $p=0.023$. A higher CRP level, as a marker of inflammation, was found to be related to amputation by Ishii and colleagues, HR 1.01, 95\% CI $1-1.02, p=0.047$, and by Plantinga and colleagues showing relative hazard $(\mathrm{RH}) 2.7,95 \%$ CI 1.72-4.23, $p<0.05$ [24]. Subjects on renal dialysis with a low mean serum albumin $(<3.3 \mathrm{~g} / \mathrm{dL})$ were also found to be at risk of amputation by Speckman and colleagues: HR 1.8, 95\% CI 1.1-3, $p<0.05$. If these subjects had diabetes, the risk was further increased: HR 3.8, 95\% CI 1.1-12.5, $p<0.05$. In the same study, Plantinga et al. reported increased albumin levels were associated with significantly decreased risk of amputation: RH 0.63, 95\% CI $0.42-0.94, p<0.05[24]$.

\section{Discussion}

This review highlights the scarcity of literature which investigates the prevalence and risk factors of amputation in patients with ESRF on renal dialysis. It revealed $1.7 \%$ to $13.4 \%$ as prevalence of LLA in patients receiving renal dialysis therapy $[20,23]$. This showed a wide variation in amputation between studies and countries. For instance, study from Japan reported lower prevalence of LLA in subjects on renal dialysis compared to higher rate in USA and Canada. This variation could suggest a better outcome amongst the Japanese cohort. This is in keeping with the finding of lower rate of coronary artery disease in the population, which is identified as an important risk factor for $\operatorname{LLA}[1,2,7]$. It could also suggest that North Americans have a lower threshold for LLA. Other reasons for the wide variation in prevalence might be due to multiple factors. For instance, Combe and colleagues conducted a large scale multinational, multicentre study which included a large number of subjects (29838) and investigated various associated risk factors such as age, ethnicity, calciphylaxis, retinopathy, and neuropathy [22]. However, the methodology used to collect the data did not differentiate between types of amputation. Though this study presented an overall worldwide $6 \%$ prevalence of amputation in renal dialysis patients, it may have been an overestimation. Plantinga and colleagues on the other hand excluded digital amputation from their data collection; this might have resulted in an underestimation of all amputations in renal dialysis patients [24]. Nevertheless, these findings warrant further studies.

Interestingly, we have identified presence of diabetes as an important single risk factor for LLA, with up to $26.5 \%$ 
TABLE 3: Summary of studies assessing risk factors of amputation in diabetic and nondiabetic patients on dialysis.

\begin{tabular}{|c|c|c|c|c|c|c|}
\hline Author & $\begin{array}{l}\text { Total patients } \\
\text { with DM }\end{array}$ & $\begin{array}{l}\text { DM patients } \\
\text { having } \\
\text { amputation }\end{array}$ & $\begin{array}{l}\text { Risk factors for amputation } \\
\text { in patients with DM }\end{array}$ & $\begin{array}{c}\text { Total } \\
\text { non-DM } \\
\text { patients }\end{array}$ & $\begin{array}{l}\text { Non-DM } \\
\text { patients } \\
\text { having } \\
\text { amputation }\end{array}$ & $\begin{array}{l}\text { Risk factors for } \\
\text { amputation in } \\
\text { patients without DM }\end{array}$ \\
\hline $\begin{array}{l}\text { Speckman et } \\
\text { al., } 2004 \text { [19] }\end{array}$ & 1751 & $104(6 \%)$ & $\begin{array}{l}\text { CVD: HR } 1.7 \text { (CI 1.1-2.6), } \\
p<0.05 \\
\text { MUR }<58.5 \%: \text { HR } 2.6 \text { (CI } \\
1.4-4.8), p<0.01\end{array}$ & 1469 & $12(1 \%)$ & $\begin{array}{l}\text { Increasing age: } \mathrm{HR} \\
1.09(\mathrm{CI} 1.02-1.2), \\
p<0.01 \\
\text { Mean serum albumin } \\
<3.5 \mathrm{~g} / \mathrm{dL}: \mathrm{HR} 3.8(\mathrm{CI} \\
1.1-12.5), p<0.01\end{array}$ \\
\hline $\begin{array}{l}\text { Combe et al., } \\
2009 \text { [22] }\end{array}$ & 11129 & $14.2 \%$ & $\begin{array}{l}\text { Peripheral neuropathy: } \\
\text { AOR } 2.23 \text { (CI 1.94-2.56), } \\
p<0.001 \\
\text { Calciphylaxis: AOR } 2.02 \\
\text { (CI 1.32-3.1), } p<0.001 \\
\text { Men: AOR } 1.69 \text { (CI } \\
1.48-1.94), p<0.001\end{array}$ & 18203 & $1.60 \%$ & $\begin{array}{l}\text { Calciphylaxis: AOR } \\
3.41 \text { (CI 1.74-6.7), } \\
p<0.001 \\
\text { Men: AOR } 2.56(\mathrm{CI} \\
\text { 1.86-3.51), } p<0.001 \\
\text { Blacks: AOR } 1.88 \text { (CI } \\
\text { 1.23-2.86), } p<0.001 \\
\text { Smoking: AOR } 1.62 \\
\text { (CI 1.11-2.37), } \\
p<0.001\end{array}$ \\
\hline
\end{tabular}

DM, diabetes mellitus; HR, hazard ratio; RH, relative hazard; AOR, adjusted odds ratio; CVD, cardiovascular disease; MUR, mean urea reduction; CI: 95\% confidence interval.

of patients with diabetes receiving renal dialysis having amputation [20]. Renal dialysis has been found to increase the risk of foot ulcer in patients with diabetes. This significant temporal association is suggested by a 3 times higher risk of having foot ulcer in the first year of starting dialysis therapy and an almost 32 times higher risk for major amputation in the first year of starting dialysis therapy [26-28]. This risk is further increased in the presence of elevated CRP $[23,24]$ and low serum albumin $[19,24]$ as well as high HbAlc level $[20,23]$ at the onset of dialysis in agreement with recent reports $[27,28]$, suggesting that acute phase reactants and poor control of diabetes worsen the prognosis further. These findings were suggested from studies which were limited to patients on haemodialysis [19-23]. On the other hand, the only study which included both peritoneal dialysis and haemodialysis [24] reported a high prevalence of limb amputation of $13 \%$; however, the authors did not provide a comparison between patients receiving haemodialysis and those on peritoneal dialysis.

Although studies have shown that peripheral arterial disease is common amongst patients on chronic dialysis therapy, the indication for bypass surgery in these patients is still a controversial topic. This is due to the high morbidity and mortality rates of these patients. Even though PTA is considered a possible procedure to treat critical limb ischemia, there is limited literature available on the prognosis of this intervention. In a 2-year follow-up prospective study on haemodialysis patients with diabetic foot wounds who were treated with PTA and minor amputation, it was found that only $41.9 \%$ of patients survived without reamputation with a 2 -year postoperative mortality rate of $38.7 \%$ [29]. This study had a small sample size of 31 haemodialysis patients; hence, it is important to explore the prognosis of PTA as treatment and prevention of amputation by doing more studies with a larger sample size. Other aspects of the review include associations between surgical procedures for vascular access and amputation. In patients with and without diabetes, both variables were increased after initiation of haemodialysis therapy. Amputations, which are potentially preventable, were associated with significant mortality amongst haemodialysis patients [30]. Thus, early interventions at primary care level have been found to lower the rate of foot complications and amputation, further stressing the need for multidisciplinary care in order to prevent adverse outcome in this group of population [31].

\section{Conclusion}

This review has demonstrated the high rate of lower limb amputation in patients with ESRF receiving dialysis therapy. It has also identified the risk factors associated with an adverse outcome, the chief amongst them being presence of diabetes. Other identified risk factors include hypoalbuminemia and elevated CRP. Thus, with early intervention in diabetic subjects, many limbs would likely be salvaged and the overall rate of adverse outcome from LLA would eventually be lowered. However, there is still a limited literature on preventative programs for LLA in subjects on renal dialysis. Furthermore, association between peritoneal dialysis and LLA is scanty as most studies were conducted on haemodialysis subjects. More studies are needed to further characterise findings in these areas.

\section{Competing Interests}

The authors report no conflict of interests. 


\section{References}

[1] R. G. Luke, "Chronic renal failure-a vasculopathic state," The New England Journal of Medicine, vol. 339, no. 12, pp. 841-843, 1998.

[2] A. M. O’Hare, D. V. Glidden, C. S. Fox, and C.-Y. Hsu, "High prevalence of peripheral arterial disease in persons with renal insufficiency: results from the national health and nutrition examination survey 1999-2000," Circulation, vol. 109, no. 3, pp. 320-323, 2004.

[3] A. M. O'Hare, P. Bacchetti, M. Segal, C.-Y. Hsu, and K. L. Johansen, "Factors associated with future amputation among patients undergoing hemodialysis: results from the dialysis morbidity and mortality study waves 3 and 4," American Journal of Kidney Diseases, vol. 41, no. 1, pp. 162-170, 2003.

[4] B. G. Jaar, B. C. Astor, J. S. Berns, and N. R. Powe, "Predictors of amputation and survival following lower extremity revascularization in hemodialysis patients," Kidney International, vol. 65, no. 2, pp. 613-620, 2004.

[5] D. J. Margolis, O. Hofstad, and H. I. Feldman, "Association between renal failure and foot ulcer or lower-extremity amputation in patients with diabetes," Diabetes Care, vol. 31, no. 7, pp. 1331-1336, 2008.

[6] A. Ndip, M. K. Rutter, L. Vileikyte et al., "Dialysis treatment is an independent risk factor for foot ulceration in patients with diabetes and stage 4 or 5 chronic kidney disease," Diabetes Care, vol. 33, no. 8, pp. 1811-1816, 2010.

[7] F. K. Port, "Morbidity and mortality in dialysis patients," Kidney International, vol. 46, no. 6, pp. 1728-1737, 1994.

[8] D. R. Whiting, L. Guariguata, C. Weil, and J. Shaw, "IDF Diabetes Atlas: global estimates of the prevalence of diabetes for 2011 and 2030," Diabetes Research and Clinical Practice, vol. 94, no. 3, pp. 311-321, 2011.

[9] IDF, Diabetes Atlas. Update 2015, International Diabetes Federation, 7th edition, 2015.

[10] P. A. Lazzarini, J. M. Gurr, J. R. Rogers, A. Schox, and S. M. Bergin, "Diabetes foot disease: the Cinderella of Australian diabetes management?" Journal of Foot and Ankle Research, vol. 5, no. 1, article 24, 2012.

[11] H. Stiegler, "Diabetic foot syndrome," Herz, vol. 29, no. 1, pp. 104-115, 2004.

[12] B. Bruhn-Olszewska, A. Korzon-Burakowska, M. GabigCimińska, P. Olszewski, A. Wegrzyn, and J. JakóbkiewiczBanecka, "Molecular factors involved in the development of diabetic foot syndrome," Acta Biochimica Polonica, vol. 59, no. 4, pp. 507-513, 2012.

[13] P. W. Eggers, D. Gohdes, and J. Pugh, "Nontraumatic lower extremity amputations in the Medicare end-stage renal disease population," Kidney International, vol. 56, no. 4, pp. 1524-1533, 1999.

[14] H. Al-Thani, A. El-Menyar, V. Koshy et al., "Implications of foot ulceration in hemodialysis patients: a 5-year observational study," Journal of Diabetes Research, vol. 2014, Article ID 945075 , 6 pages, 2014.

[15] N. Tentolouris, S. Al-Sabbagh, M. G. Walker, A. J. M. Boulton, and E. B. Jude, "Mortality in diabetic and nondiabetic patients after amputations performed from 1990 to 1995: a 5-year followup study," Diabetes Care, vol. 27, no. 7, pp. 1598-1604, 2004.

[16] R. Sinha, W. J. A. van den Heuvel, and P. Arokiasamy, "Factors affecting quality of life in lower limb amputees," Prosthetics and Orthotics International, vol. 35, no. 1, pp. 90-96, 2011.

[17] U. H. Malabu, V. Manickam, G. Kan, S. L. Doherty, and K. S. Sangla, "Calcific uremic arteriolopathy on multimodal combination therapy: still unmet goal," International Journal of Nephrology, vol. 2012, Article ID 390768, 6 pages, 2012.

[18] W. G. Goodman, J. Goldin, B. D. Kuizon et al., "Coronary-artery calcification in young adults with end-stage renal disease who are undergoing dialysis," The New England Journal of Medicine, vol. 342, no. 20, pp. 1478-1483, 2000.

[19] R. A. Speckman, D. L. Frankenfield, S. H. Roman et al., "Diabetes is the strongest risk factor for lower-extremity amputation in new hemodialysis patients," Diabetes Care, vol. 27, no. 9, pp. 2198-2203, 2004.

[20] H. Locking-Cusolito, L. Harwood, B. Wilson et al., "Prevalence of risk factors predisposing to foot problems in patients on hemodialysis," Nephrology Nursing Journal, vol. 32, no. 4, pp. 373-384, 2005.

[21] N. C. Reddy, S. M. Korbet, J. A. Wozniak, S. L. Floramo, and E. J. Lewis, "Staff-assisted nursing home haemodialysis: patient characteristics and outcomes," Nephrology Dialysis Transplantation, vol. 22, no. 5, pp. 1399-1406, 2007.

[22] C. Combe, J. M. Albert, J. L. Bragg-Gresham et al., "The burden of amputation among hemodialysis patients in the dialysis outcomes and practice patterns study (DOPPS)," American Journal of Kidney Diseases, vol. 54, no. 4, pp. 680-692, 2009.

[23] H. Ishii, Y. Kumada, H. Takahashi et al., "Impact of diabetes and glycaemic control on peripheral artery disease in Japanese patients with end-stage renal disease: long-term follow-up study from the beginning of haemodialysis," Diabetologia, vol. 55, no. 5, pp. 1304-1309, 2012.

[24] L. C. Plantinga, N. E. Fink, J. Coresh et al., "Peripheral vascular disease-related procedures in dialysis patients: predictors and prognosis," Clinical Journal of the American Society of Nephrology, vol. 4, no. 10, pp. 1637-1645, 2009.

[25] A. Liberati, D. G. Altman, J. Tetzlaff et al., "The PRISMA statement for reporting systematic reviews and meta-analyses of studies that evaluate healthcare interventions: explanation and elaboration," The British Medical Journal, vol. 339, Article ID b2700, 2009.

[26] F. L. Game, S. Y. Chipchase, R. Hubbard, R. P. Burden, and W. J. Jeffcoate, "Temporal association between the incidence of foot ulceration and the start of dialysis in diabetes mellitus," Nephrology Dialysis Transplantation, vol. 21, no. 11, pp. 32073210, 2006.

[27] N. J. Jones, J. Chess, S. Cawley, A. O. Phillips, and S. G. Riley, "Prevalence of risk factors for foot ulceration in a general haemodialysis population," International Wound Journal, vol. 10, no. 6, pp. 683-688, 2013.

[28] M. Kaminski, N. Frescos, and S. Tucker, "Prevalence of risk factors for foot ulceration in patients with end-stage renal disease on haemodialysis," Internal Medicine Journal, vol. 42, no. 6, pp. e120-e128, 2012.

[29] K. Matsuzaki, A. Miyamoto, N. Hakamata et al., "Diabetic foot wounds in haemodialysis patients: 2-year outcome after percutaneous transluminal angioplasty and minor amputation," International Wound Journal, vol. 9, no. 6, pp. 693-700, 2012.

[30] M. Martinez, R. Last, E. I. Agaba et al., "Surgical procedures before and after starting chronic hemodialysis in a predominantly male population with high prevalence of diabetes," International Journal of Artificial Organs, vol. 35, no. 9, pp. 648654, 2012.

[31] T. Pliakogiannis, S. Bailey, S. Cherukuri et al., "Vascular complications of the lower extremities in diabetic patients on peritoneal dialysis," Clinical Nephrology, vol. 69, no. 5, pp. 361$367,2008$. 


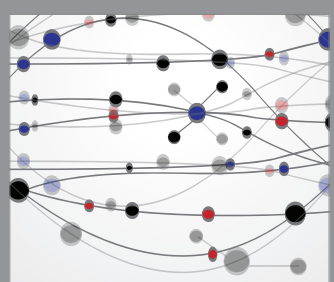

The Scientific World Journal
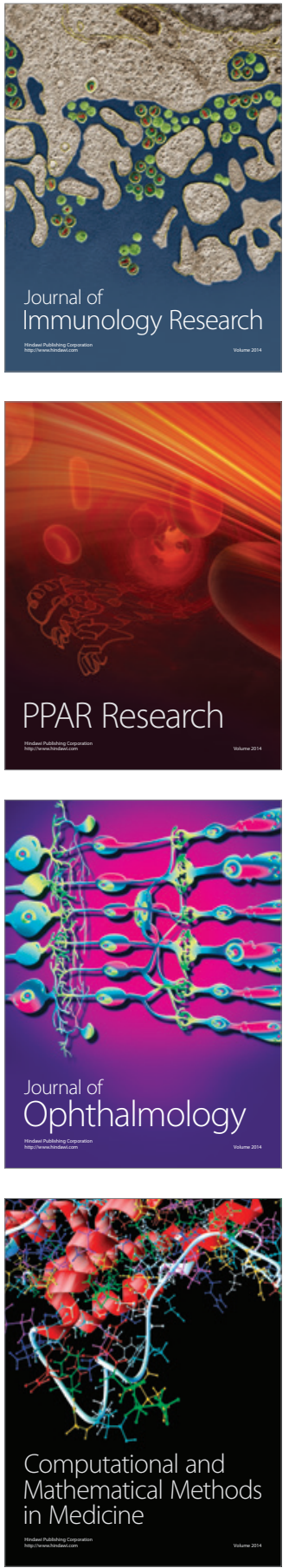

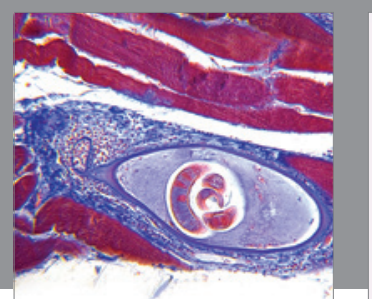

Gastroenterology Research and Practice

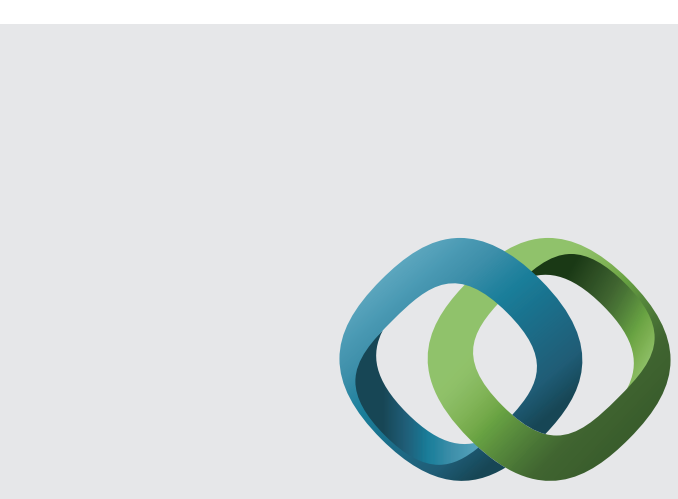

\section{Hindawi}

Submit your manuscripts at

http://www.hindawi.com
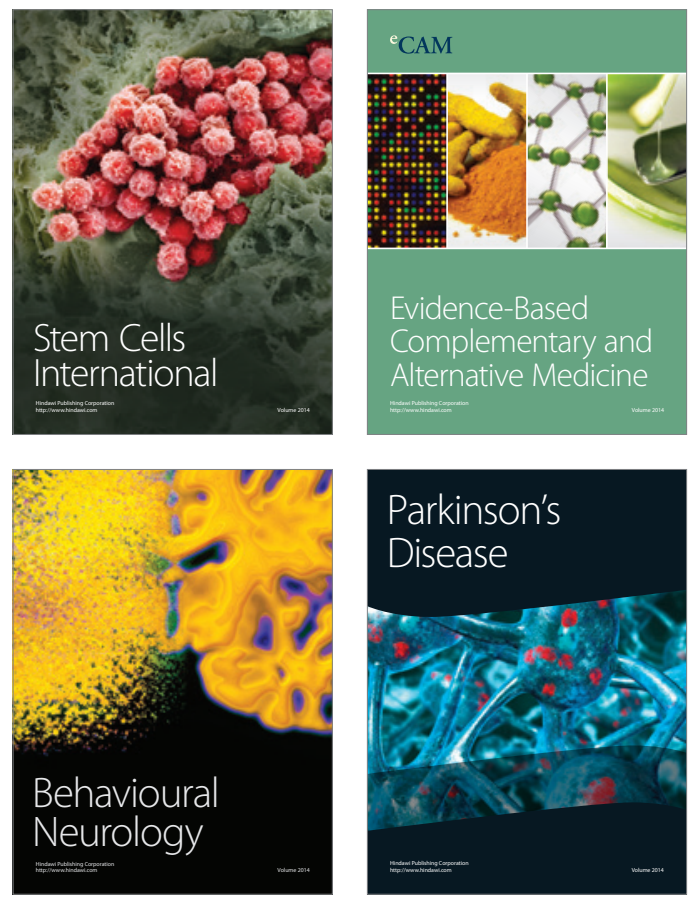
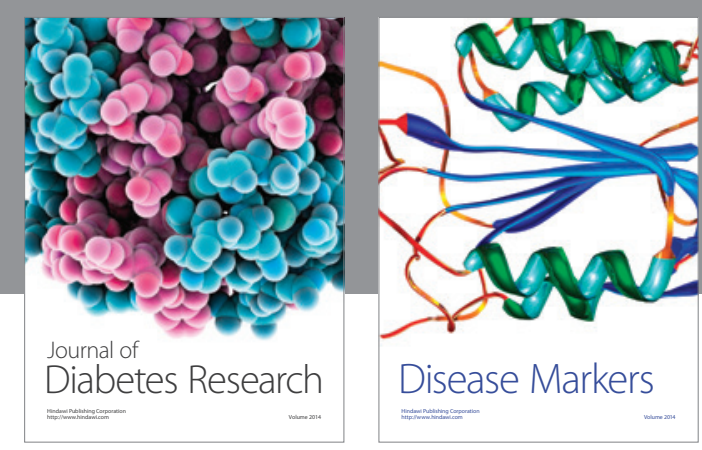

Disease Markers
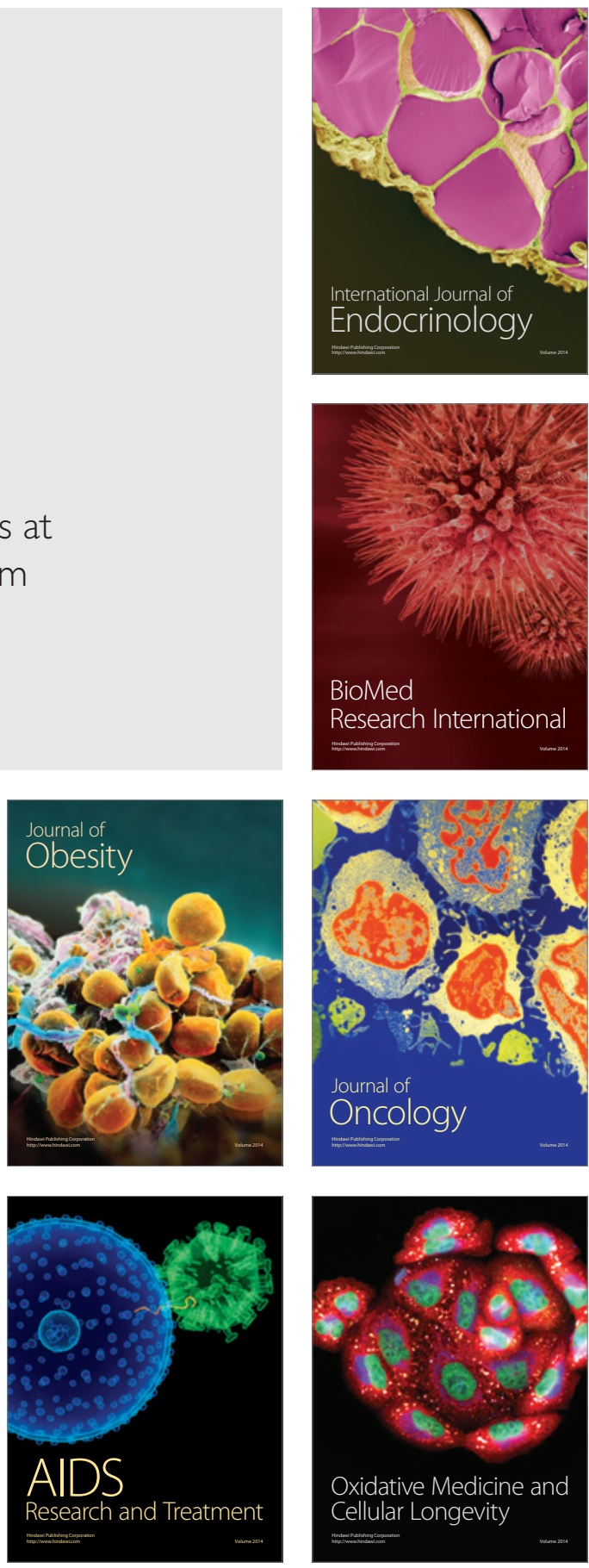